Document downloaded from:

http://hdl.handle.net/10251/103608

This paper must be cited as:

Traffano-Schiffo, MV.; Aguirre Calvo, TR.; Castro Giraldez, M.; Fito Suñer, PJ.; Santagapita, PR. (2017). Alginate Beads Containing Lactase: Stability and Microstructure. Biomacromolecules. 18(6):1785-1792. doi:10.1021/acs.biomac.7b00202

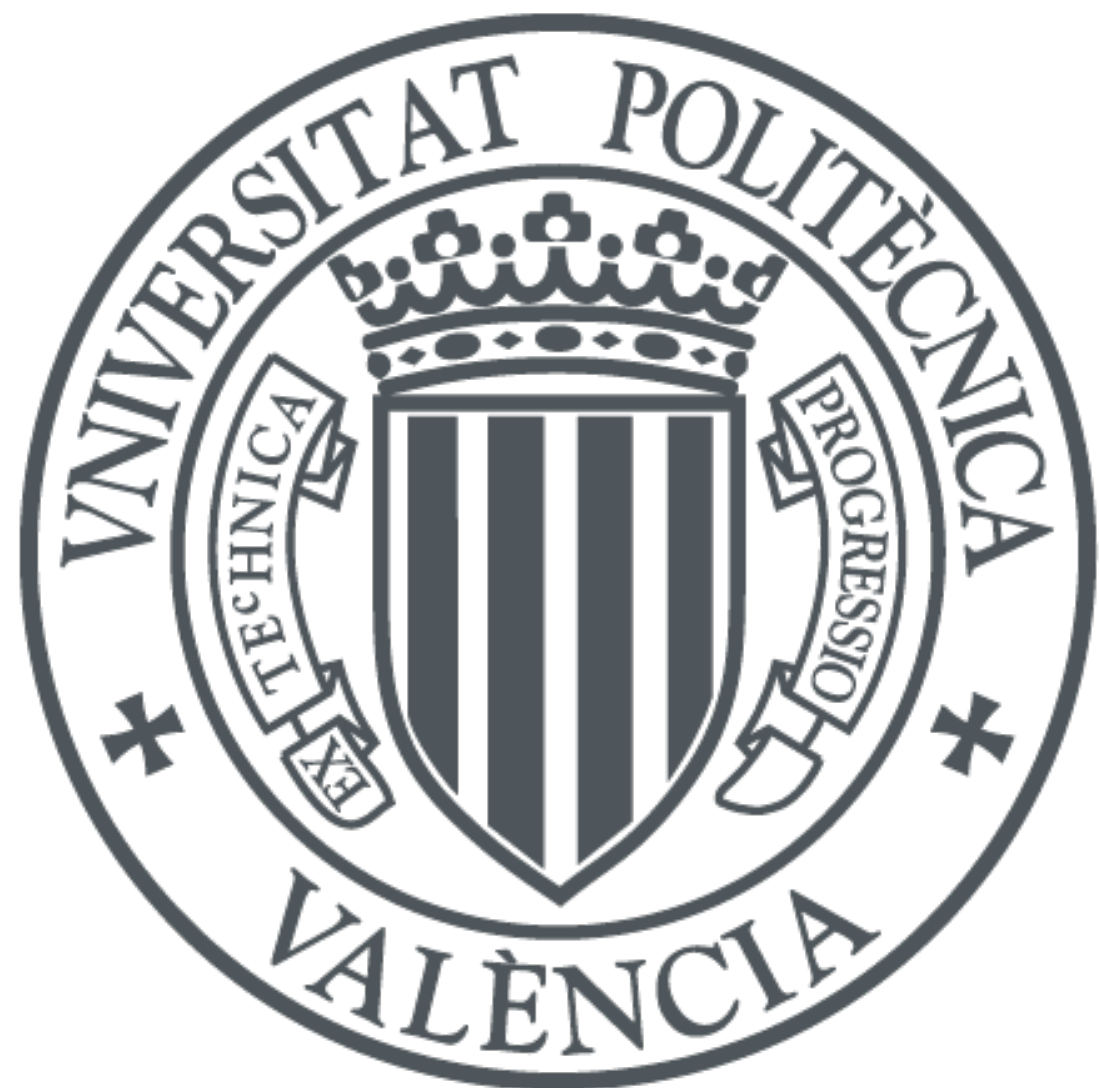

The final publication is available at

https://doi.org/10.1021/acs.biomac.7b00202

Copyright American Chemical Society

Additional Information 


\title{
Alginate beads containing lactase: stability and microstructure
}

\author{
Maria Victoria Traffano-Schiffo, ${ }^{\dagger}$ Tatiana R. Aguirre Calvo, ${ }^{\S}$ \\ Marta Castro-Giraldez, ${ }^{\dagger}$ Pedro J. Fito, ${ }^{\dagger}$ and Patricio R. Santagapita ${ }^{\S, \neq *}$
}

${ }^{\dagger}$ Instituto Universitario de Ingeniería de Alimentos para el Desarrollo, Universidad Politécnica de Valencia, Camino de Vera s/n, 46022 Valencia, Spain.

${ }^{\S}$ Universidad de Buenos Aires, Facultad de Ciencias Exactas y Naturales, Departamentos de Industrias y Química Orgánica (FCEN-UBA), Buenos Aires, Argentina.

‡ Consejo Nacional de Investigaciones Científicas y Técnicas (CONICET), Buenos Aires, Argentina.

Corresponding Author:

* Phone/ Fax: 54114576 3366; e-mail: prs@di.fcen.uba.ar 


\section{ABSTRACT}

$\beta$-galactosidase (lactase) is a widely used enzyme in food industry; however, it has low stability against thermal and mechanical treatments. Due to this, the purpose of present research was to analyze the encapsulation of lactase in alginate-Ca(II) beads in order to maintain its enzymatic activity towards freezing, freezing/thawing and storage. Also, the effect of the addition of trehalose, arabic and guar gums and its influence in the microstructure as well as in thermal properties and molecular mobility were studied. Lactase was successfully encapsulated in alginate-Ca(II) beads and the inclusion of trehalose was critical for activity preservation towards treatments, being improved in guar gum-containing systems. The gums increased the $\mathrm{T}_{\mathrm{m}}$ ' values which represents a valuable technological improvement. Finally, the presence of secondary excipients affected the microstructure, showing rods with smaller outer diameter and with lower compactness than alginate-Ca(II) beads. Also, beads composition greatly affects the size, shape and relaxations times.

Keywords: alginate beads, encapsulation, enzyme stability, $\beta$-galactosidase, microstructure, Small-Angle X-ray scattering. 


\section{INTRODUCTION}

$\beta$-galactosidase or commonly known as lactase is a widely used enzyme in the food industry because is able to catalyze the bioconversion of lactose ( $\beta$-D-Galactose-(1-4)-D-Glucose) into glucose and galactose. ${ }^{1,2}$ Several applications of $\beta$-galactosidase have been reported in recent years, such as the valorization of cheese whey which reduce the environmental impact, ${ }^{3}$ the improvement of ice creams creaminess and the sweetness of dairy products due to the lactose hydrolysis $^{4}$ and the producing of lactose-free fresh dairy products in order to satisfy the needs of lactose intolerance people. ${ }^{5-7}$ However, enzyme stability upon treatment and dosification can be improved. In this context, the encapsulation of $\beta$-galactosidase in hydrogels such as alginate represents a promising tool.

Alginate consists of $\alpha$-L-guluronic acid and $\beta$-D-mannuronic acid residues and is one of the most used anionic polyelectrolyte due to its gelation properties in presence of divalent cations (usually $\mathrm{Ca}^{2+}$ for food science applications), which interact ionically, crosslinking a pair of $\alpha$-Lguluronic acids blocks within the alginate chains. ${ }^{8,9}$ Alginate-Ca(II) shows important advantages because its biocompatibility, easy availability, low cost, resistance to contamination, simplicity and its applicability in food industry due to its non-toxic nature. ${ }^{10,11}$ Nevertheless, it shows disadvantages associated to its low mechanical strength, the presence of macropores and especially some technological problems i.e. the enzymatic activity losses during beads formation and the low resistance to physical treatments such as freezing and dehydration. ${ }^{11}$ Therefore, several researchers have demonstrated that the combined use of alginate with sugars and/or other biopolymers allow to increase the resistance of the beads. ${ }^{12,13}$

Trehalose (1- $\alpha$-glucopyranosyl-1- $\alpha$-glucopyranoside) is a non-reducing disaccharide which acts as a protecting agent against to stress conditions such as heat treatments, dehydration or 
freezing. ${ }^{14,15}$ On the other hand, it has been demonstrated that the addition of biopolymers such as arabic gum (arabinogalactan-protein type polysaccharide) and guar gum (galactomannan) as second matrix ingredients increase the stability of encapsulated systems. ${ }^{16-18}$

One of the most precise and powerful techniques to evaluate the microstructure of alginate hydrogels is the Small-Angle X-ray scattering (SAXS). SAXS method is able to analyze differences in electron density in hydrogels crosslinked networks from wavelengths of sub-

nanometers up to $100 \mathrm{~nm}$, providing information of the biopolymers morphology. ${ }^{19}$ The main parameters of SAXS analysis are the rod cross-sectional radius (R), the fractal dimension at distances higher than $\mathrm{R}\left(\alpha_{1}\right)$, which describes the junction zone, and the fractal dimension at distances lower than $\mathrm{R}\left(\alpha_{2}\right)$ describing the nanostructure within the rods. ${ }^{20,21}$

The aim of this research is to study the viability of the encapsulation of $\beta$-galactosidase in alginate beads maintaining its enzymatic activity. In addition, analyze the influence in the formulation by adding other compounds (sugars and biopolymers) in the microstructure and the stability of the enzyme.

\section{MATERIAL AND METHODS}

\section{Materials}

The employed materials were listed below: sodium alginate (Algogel 5540) from Cargill S.A. (San Isidro, Buenos Aires, Argentina), molecular weight of $1.97 \cdot 10^{5} \mathrm{~g} / \mathrm{mol}$ and mannuronate/guluronate ratio of 0.6; D-trehalose dihydrate (Hayashibara Co., Ltd., Shimoishii, Okayama, Japan/Cargill Inc., Mineapolis, Minnesota, USA) molecular weight of 378 g/mol; guar gum (Cordis S.A., Villa Luzuriaga, Buenos Aires, Argentina) molecular weight of 220.000 g/mol and a mannose/galactose ratio of 1.8; arabic gum (Biopack, Zárate, Buenos Aires, Argentina) 
molecular weight of $250.000 \mathrm{~g} / \mathrm{mol}$ and a purity of $99 \%$; $\beta$-galactosidase (lactase) from Aspergillus Oryzae (8.0 U/mg) (Sigma-Aldrich Co, Ltd, Saint Louis, USA). One enzymatic unit was defined as the amount of enzyme able to hydrolyze $1.0 \mu \mathrm{mol}$ of lactose per minute at $\mathrm{pH} 4.5$ at $30^{\circ} \mathrm{C}$.

\section{Gel beads preparation}

The formulations of the initial emulsions used for the different beads systems were: alginate $1 \%(\mathrm{w} / \mathrm{v})$, alginate $1 \%(\mathrm{w} / \mathrm{v})$ with trehalose $20 \%(\mathrm{w} / \mathrm{v})$, alginate $1 \%(\mathrm{w} / \mathrm{v})$ with $20 \%(\mathrm{w} / \mathrm{v})$ trehalose and mixed with $0.25 \%(\mathrm{w} / \mathrm{v})$ of arabic or guar gum, respectively. The initial solutions were prepared in $0.1 \mathrm{M}$ acetate buffer $\mathrm{pH}$ 3.8. Lactase solution was prepared in the same buffer to a final concentration of $0.775 \mathrm{mg} / \mathrm{mL}$. Finally, the enzyme and the initial solutions were mixed carefully and maintained at $4 \pm 1{ }^{\circ} \mathrm{C}$ in order to avoid enzyme activity losses due to mechanical forces and temperature conditions, respectively. Taking into account that the isoelectric point of the enzyme was $4.61^{22,23}$ and the $\mathrm{pk}_{\mathrm{a}}$ values of alginate (3.38 and 3.65), ${ }^{13}$ the buffer acetate at $\mathrm{pH}$ 3.8 was used in order to obtain an electrostatic interaction between the alginate (negatively charged) and the enzyme (positively charged).

Beads were prepared according to the drop method described by Austin, Bower, \& Muldoon ${ }^{24}$ with some modifications. A peristaltic pump (Boading Longer Precision Pump Co., Ltd., China) was used to drop $10 \mathrm{~mL}$ of the initial solution into $100 \mathrm{~mL}$ of $\mathrm{CaCl}_{2}$ solution at a concentration of $2.5 \%(w / v)$ prepared in the buffer acetate described above (with or without trehalose $20 \%$ $(w / v))$, with constant stirring in a cold bath and using needle with $0.25 \mathrm{~mm}$ diameter and $6 \mathrm{~mm}$ length (Novofine 32 G, Novo Nordisk A/S, Bagsvaerd, Denmark). The distance between the 
needle and the $\mathrm{CaCl}_{2}$ was $6 \mathrm{~cm}$ and $9.0 \pm 0.1 \mathrm{rpm}$. After beads generation, they were maintained 15 min in $\mathrm{CaCl}_{2}$ solution and after that washed 5 times with cold water.

Samples were codified as follows: EA: Enzyme/Alginate; EAT: Enzyme/Alginate/Trehalose;

EATAG: $\quad$ Enzyme/Alginate/Trehalose/Arabic gum and EATGG:

Enzyme/Alginate/Trehalose/Guar gum.

Thermal Treatments

Freezing

Wet beads were frozen at $-18{ }^{\circ} \mathrm{C}$ by using a conventional freezer during $24 \mathrm{~h}$.

Freeze/thaw cycles

The Freeze/thaw treatment was performed freezing the beads during 1 min using liquid nitrogen (at $-196{ }^{\circ} \mathrm{C}$ ) and thawing in a conventional fridge at $4{ }^{\circ} \mathrm{C}$ during $30 \mathrm{~min}$; this procedure was repeated 4 times for each system.

Storage

In order to analyze the stability of the enzyme during the storage, beads were maintained at 4 ${ }^{\circ} \mathrm{C}$ in a conventional fridge during $48 \mathrm{~h}$.

Beads characterization

Digital image analysis

The size and shape of the beads was analyzed through digital images captured by a digital camera coupled to a binocular microscope and analyzed by the free license software ImageJ (http://rsbweb.nih.gov/ij/), as described by Aguirre Calvo \& Santagapita ${ }^{25}$. The Feret's diameter (size) corresponds to the longest distance between any two points along the bead boundary. The 
circularity indicates how similar the bead is to a circle. At least 40 beads were analyzed by applying the "analyze particle" command of the software. In order to increase the contrast of the images, the beads have been stained with erythrosine $1 \%(\mathrm{w} / \mathrm{v})$. The ImageJ software was calibrated to transform the measured pixels in length units $(\mathrm{mm})$ by taking pictures of a caliper section.

Water content and water activity

Water content of the beads was obtained gravimetrically by the difference in weight before and after drying in vacuum oven for $48 \mathrm{~h}$ at $96 \pm 2{ }^{\circ} \mathrm{C} .{ }^{25}$ Water activity $\left(\mathrm{a}_{\mathrm{w}}\right)$ was determined by a dew point Hygrometer Decagon (Aqualab ${ }^{\circledR}$, series 3 TE, Decagon Devices, Pullman, WA, USA). A special sample holder was used to reduce the quantity of beads needed. A calibration curve was performed with salts with known $\mathrm{a}_{\mathrm{w}}$ (between 0.25 and 1 ). All determinations were made in triplicate.

\section{Microstructure characterization}

The microstructure characterization was performed by small angle X-ray scattering (SAXS) at the LNLS SAXS2 beamline in Campinas, Brazil, working at $\lambda=0.1488 \mathrm{~nm}$. The wave vector range was selected in the range $0.096 \mathrm{~nm}^{-1}<\mathrm{q}<2.856 \mathrm{~nm}^{-1}$. All the alginate-Ca(II) beads analyzed showed isotropic scattering and were modeled as a fractal system composed of rod-like structures, although the rigorous interpretation of experimental results as indicating "fractality" requires many orders of magnitude of power-law scaling. ${ }^{20}$ Three parameters were analyzed: i) $\alpha_{1}$, the fractal dimension at distances higher than $\mathrm{R}$, which describes the multiplicity of the junction zone, at $\mathrm{q}<0.28$; ii) $\alpha_{2}$, the fractal dimension at distances lower than $\mathrm{R}$, at $\mathrm{q}>0.55$, 
describing the degree of compactness within the rods. Parameters $\alpha_{1}$ and $\alpha_{2}$ were evaluated from the slope of the scattering intensity averaged along azimuthal angles versus the scattering vector q in the $\log -\log$ scale; iii) $R$, the outer radius of the fibrils, which is given by $R=R_{g} \sqrt{ } 2, R_{g}$ being the mean gyration radius in the cross-section of the rods, which is obtained from the maximum exhibit by the Kratky plot at $\mathrm{q} \approx 1 / \mathrm{Rg}$. The Kratky plot: scattering intensity multiplied by the square modulus of the scattering vector, $\mathrm{I}(\mathrm{q}) \cdot \mathrm{q}^{2}$, as a function of the modulus of the scattering vector, q, gives a maximum value at the intersection of power law regions and allows the calculation of parameter R. All measurements were made in triplicate.

\section{$\beta$-Galactosidase activity}

The enzyme activity was evaluated based on the absorbance values at $420 \mathrm{~nm}$ by using a Jasco V-630 UV-VIS spectrophotometer (JASCO Inc., Maryland, USA) at room temperature and following the method described by Park, Santi, \& Pastore, ${ }^{26}$ with some modifications.

Firstly, each analysis was performed using 9 beads which were dissolved into $0.25 \mathrm{~mL}$ of 0.1 $\mathrm{M}$ citrate buffer $\mathrm{pH} 4.5$ during $2 \mathrm{~h}$ at $4{ }^{\circ} \mathrm{C}$ and without stirring in order to avoid enzymatic activity losses. Subsequently, $0.25 \mathrm{~mL}$ of o-nitrophenyl- $\beta$-D-galactopyranoside (ONPG) (Sigma Chemical Co.) prepared with $0.1 \mathrm{M}$ acetate buffer $\mathrm{pH} 3.8$ was added and incubated during 15 min at $33^{\circ} \mathrm{C}$. Finally, the reaction was stopped adding $0.5 \mathrm{~mL}$ of sodium carbonate $10 \%(\mathrm{w} / \mathrm{v})$ and $1.75 \mathrm{~mL}$ of distilled water for subsequent measurement of o-nitrophenol (ONP) at $420 \mathrm{~nm}$. Measurements were made in triplicate.

The effect of the composition of the beads on enzyme stability immediately after beads generation was evaluated through an activity index calculated with the following equation:

$$
\text { Activity Index }(\%)=\frac{\text { Activity }_{i}}{\text { Activity }_{E A}} \times 100
$$


Where Activity $_{i}$ corresponds to the activity of any the studied systems (EA, EAT, EATAG or EATGG) and Activity $_{E A}$ is the activity of the EA system.

On the other hand, in order to analyze the activity of the beads after thermal treatments, the remaining activity was calculated as follows:

$$
\text { Remaining Activity (\%) }=\frac{\text { Activity }_{t}}{\text { Activity }_{0}} \times 100
$$

Where Activity $_{t}$ is the activity value of each system obtained after a given treatment and Activity $_{0}$ is related to the activity of the same system before the treatment.

\section{Differential scanning calorimetry (DSC)}

Glass transition temperature $\left(T_{g}\right)$, the variations in heat capacity at $T_{g}(\Delta c p)$, the onset temperatures of ice melting $\left(\mathrm{T}_{\mathrm{m}}{ }^{\prime}\right)$ and the endothermal melting peak were determined by differential scanning calorimetry (DSC) by means of a Mettler Toledo 822 equipment (Mettler Toledo AG, Urdorf, Switzerland) and STARe Thermal Analysis System version 3.1 software (Mettler Toledo AG). The instrument was calibrated using standard compounds (indium and zinc) of defined melting point and heat of melting.

All measurements were made in duplicate with $14-23 \mathrm{mg}$ sample mass (10 beads), using hermetically sealed aluminum pans of $40 \mu \mathrm{l}$ inner volume (Mettler), heated from $-100{ }^{\circ} \mathrm{C}$ to 50 ${ }^{\circ} \mathrm{C}$ at $10{ }^{\circ} \mathrm{C} / \mathrm{min}$; an empty crucible was used as a reference. Measurements were made in duplicate.

The unfreezable water $\left(\mathrm{g}_{\mathrm{nfw}} / \mathrm{g}_{\mathrm{T}}\right)$ was calculated as follows: ${ }^{27}$

$$
x_{n f w}=1-\frac{\Delta H}{\Delta H_{i c e}}
$$


Where $\Delta H\left(\mathrm{~J} / \mathrm{g}_{\mathrm{w}}\right)$ corresponds to the difference of crystallization and melting heats of water per gram of sample obtained by the integration of crystallization and melting peaks, respectively and $\Delta H_{i c e}$ is the latent heat of melting of pure water at $0{ }^{\circ} \mathrm{C}(-333 \mathrm{~J} / \mathrm{g})$.

\section{Low Field Nuclear Magnetic Resonance (LF-NMR)}

Transversal or spin-spin relaxation times $\left(T_{2}\right)$ and longitudinal relaxation or spin-lattice $\left(T_{1}\right)$ were measured by time resolved low field proton nuclear magnetic resonance ( $\left.{ }^{1} \mathrm{H}-\mathrm{LF}-\mathrm{NMR}\right)$ in a Bruker Minispec mq20 (Bruker Biospin Gmbh, Rheinstetten, Germany) with a 0.47 T magnetic field operating at a resonance frequency of $20 \mathrm{MHz}$. All samples were previously equilibrated at $25.00 \pm 0.01^{\circ} \mathrm{C}$ in a thermal bath (Haake, model Phoenix II C35P, Thermo Electron Corporation Gmbh, Karlsruhe, Germany). All determinations were made in duplicate.

$T_{1}$ was obtained by inversion recovery sequence. ${ }^{28}$ The following settings were used: first and final pulse separation of $2 \mathrm{~ms}$ and $10 \mathrm{~s}$, scans $=4$, number of points $=20$, recycled delay $=5$, gain $=81-84 \mathrm{~dB}$; phase cycling was used. A monoexponential equation was used for fitting

curves. $T_{2}$ was obtained by using Carr-Purcell-Meiboom-Gill (CPMG) sequence, ${ }^{29,30}$ with the following setting: $\tau=2 \mathrm{~ms}$, scans $=4$, number points $=500$, dummy shots $=0$, gain $=83 \mathrm{~dB}$; phase cycling was used. A biexponential decay was used to fitting curves, as previously reported. ${ }^{31}$

\section{Statistical analyses}

The statistical analyses were performed by one-way ANOVA with Tukey`s post test by using Prism 6 (GraphPad Software Inc., San Diego, CA, USA) in order to determine significant differences between the mean values of beads of different composition on the measured 
parameters. When the analysis of variance indicates differences among means, a $t$ test was used to differentiate means with $95 \%$ of confidence $(p<0.05)$.

\section{RESULTS AND DISCUSSION}

Beads characterization

Spherical alginate beads were obtained by the dropping method. The size and shape of the beads were analyzed by measuring Feret's diameter and circularity by optical microscopy and a digital image processing technique. Figure 1 shows Feret's diameter (Figure 1a) and the circularity (Figure 1b) obtained for the beads of different composition. All the beads showed a Feret's diameter close to $1.5 \mathrm{~mm}$, similar to the one reported in other works. ${ }^{11,13}$ However, the addition of gums resulted in a significant increment of the size, reaching $1.628 \pm 0.072 \mathrm{~mm}$ for guar gum containing beads. The increase in viscosity produced by the addition of guar gum ${ }^{32}$ and the well known interfacial properties of arabic gum (due to its protein-polysaccharide combined structure $^{33}$ ) directly affects the surface tension of the drops prior to gelation, which could be responsible for the higher size observed. All beads showed high circularity values (near 0.7), very similar among all the systems. The inclusion of gums showed opposite behavior: arabic gum containing beads showed the highest circularity, and the guar gum containing ones the lowest. This is consistent with the previous discussion: an increment in viscosity will impact on bead size and shape (having a drop-like form, accounting for it higher deformation); instead, a reduction of the interfacial properties ${ }^{33}$ will reduce the deformation, even increasing the circularity. 

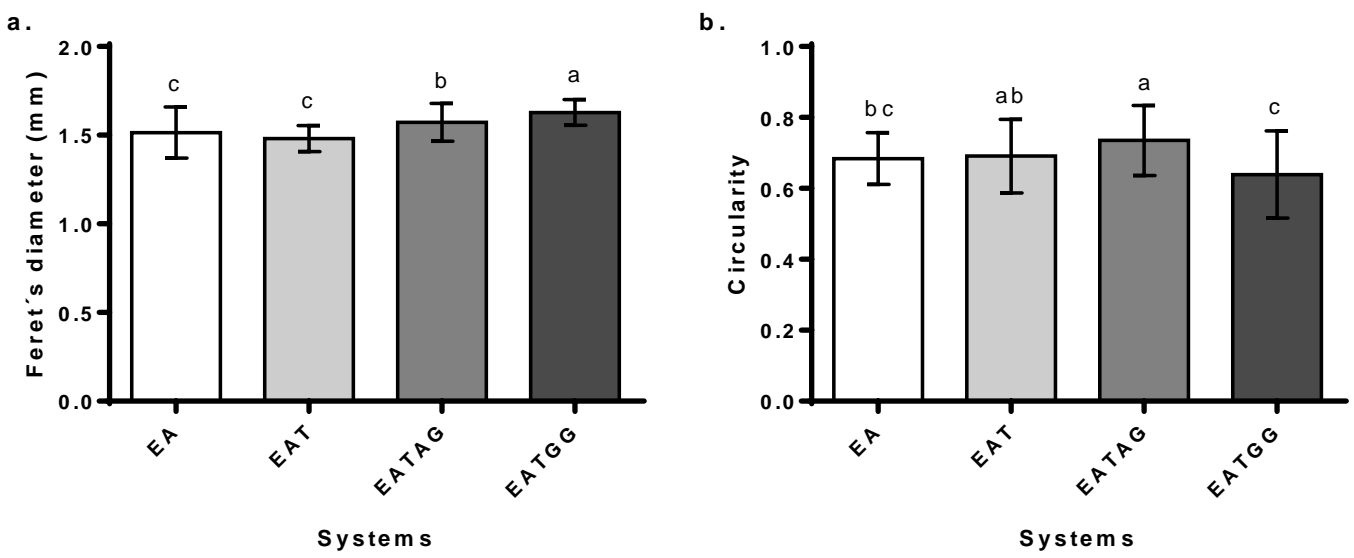

Figure 1. a) Feret's diameter and b) circularity of the beads with different composition. E: enzyme; A: alginate; T: trehalose; AG: arabic gum; GG: guar gum. Standard deviation values are included. Different letters on the columns (a-c) indicate significant differences $(p<0.05)$.

Taking into account the high influence of the water in the structure and the stability of the systems, water content and $a_{w}$ of beads were determined. As Table 1 shows, the $a_{w}$ values obtained were between 0.939 and 0.949 , without significant differences between beads of different composition. However, the beads containing trehalose showed significantly lower values of moisture with regard to alginate beads, as previously reported by Santagapita et al. ${ }^{13}$ This difference could be due to the fact that the trehalose is a polyol, able to make multiple hydrogen bonds, replacing water molecules. On the other hand, the addition of biopolymers (guar and arabic gums) to alginate/trehalose system produced higher moisture values $(\mathrm{p}<0.05)$ due to its capability to interact with water molecules. 
Table 1. Water activity and moisture content $\left(\mathrm{kg}_{\mathrm{w}} / \mathrm{kg}_{\mathrm{T}}\right)$ obtained for wet beads. E: enzyme; A: alginate; T: trehalose; AG: arabic gum; GG: guar gum. Standard deviation values are included.

\begin{tabular}{|c|ccc|ccc|}
\hline Systems & \multicolumn{3}{|c|}{$\mathrm{a}_{\mathrm{w}}$} & \multicolumn{3}{c|}{$\mathrm{x}_{\mathrm{w}}\left(\mathrm{kg}_{\mathrm{w}} / \mathrm{kg}_{\mathrm{T}}\right)$} \\
\hline EA & 0.939 & \pm & $0.006^{\mathrm{a}}$ & 0.9683 & \pm & $0.0088^{\mathrm{a}}$ \\
EAT & 0.944 & \pm & $0.008^{\mathrm{a}}$ & 0.852 & \pm & $0.005^{\mathrm{c}}$ \\
EATAG & 0.949 & \pm & $0.003^{\mathrm{a}}$ & 0.871 & \pm & $0.002^{\mathrm{b}}$ \\
EATGG & 0.949 & \pm & $0.001^{\mathrm{a}}$ & 0.872 & \pm & $0.003^{\mathrm{b}}$ \\
\hline
\end{tabular}

${ }^{\mathrm{a}-\mathrm{c}}$ Different letters on the columns indicate significant differences between means $(p<0.05)$.

\section{Microstructure analysis}

The microstructure of the hydrogel beads was investigated by SAXS where R, $\alpha_{1}$ and $\alpha_{2}$ parameters were obtained. Figure 2 shows the SAXS scattering profile, indicating the power law regimes at a low and high $\mathrm{q}$ value. Also, the characteristic size of the rods composing the structure is deduced from the maxima observed on Kratky plots, which is included as an inset. 


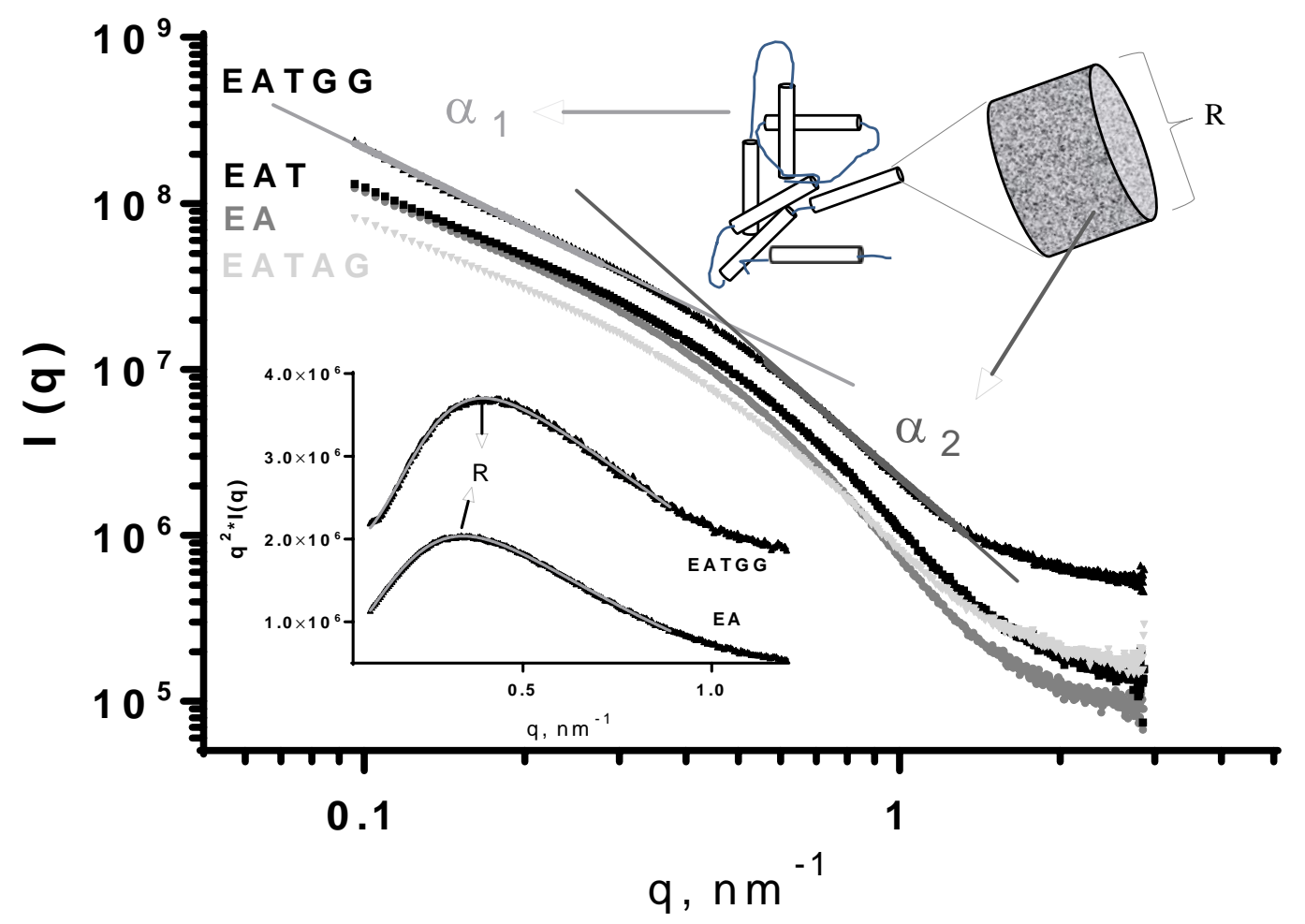

Figure 2. log-log SAXS profile plots of representative samples of alginate-Ca(II) hydrogels containing lactase with the addition of trehalose and biopolymers. Parameters $\alpha_{1}$ and $\alpha_{2}$ were evaluated from the slope of the scattering intensity at low and high values of q, respectively, and the radius of gyration of the rods (parameter R) was obtained from the Kratky plot (inset). A representative scheme of the parameters is also included. E: enzyme; A: alginate; T: trehalose; AG: arabic gum; GG: guar gum.

$\alpha_{1}$ reflects the degree of interconnection of the rods which depends on the composition of the beads. $\alpha_{1}$ can take values between 1 and 2 . A representative scheme of the parameter can be observed in Figure 2. When $\alpha_{1}=1$, it can be related to randomly oriented rods and when $\alpha_{1}=2$ means that the rods are interconnected. ${ }^{20}$ Figure 3 a shows the $\alpha_{1}$ parameter for all the systems, 
where no significant differences can be appreciated, with mean values around 1.45. This suggests that the addition of any excipients did not affect the interconnection of the structure via the coordination of carboxylic groups belonging to alginate chains, as the egg-box model predicts. ${ }^{34}$

Figure $3 \mathrm{~b}$ shows the $\mathrm{R}$ parameter deduced from Kratky plot which indicates the size of the rods. The values obtained for alginate-Ca(II) gels were in agreement to previous observation. ${ }^{20,21}$ However, significant differences between enzyme/alginate and the rest of the samples can be appreciated, being much smaller for trehalose containing beads. These differences could be due to a different compactness of the nanostructures of the hydrogels on the rods. Then, $\alpha_{2}$ was analyzed and, as shown in Figure 3 c, there were significant differences between the beads containing trehalose with regard to alginate beads, being also smaller for trehalose containing beads. Then, the addition of trehalose and/or gums affected the extent of the rod formation, reducing the outer radius of the fibrils as well as their compactness. On the other hand, the compactness was further reduced by the addition of gums, which could be explained by the produced steric hindrance along alginate chains. The changes at microstructural level could impact the enzyme stability, by affecting the extent of interaction between the excipients (being involved inside the rods, or outside of them) and the enzyme. This issue will be analyzed in the next section. 


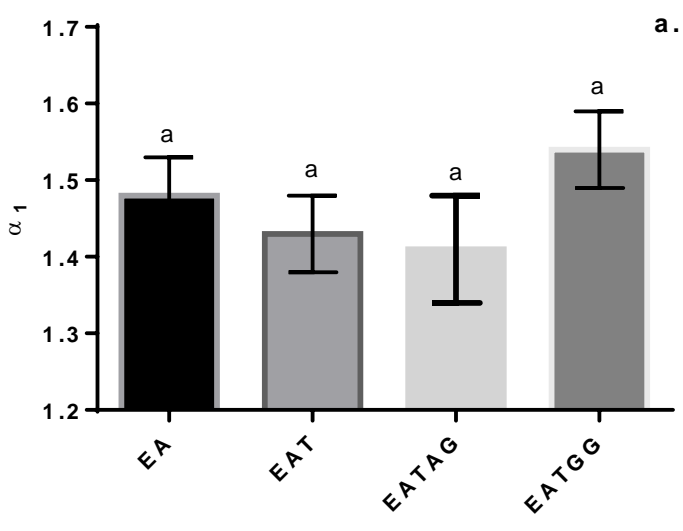

a.
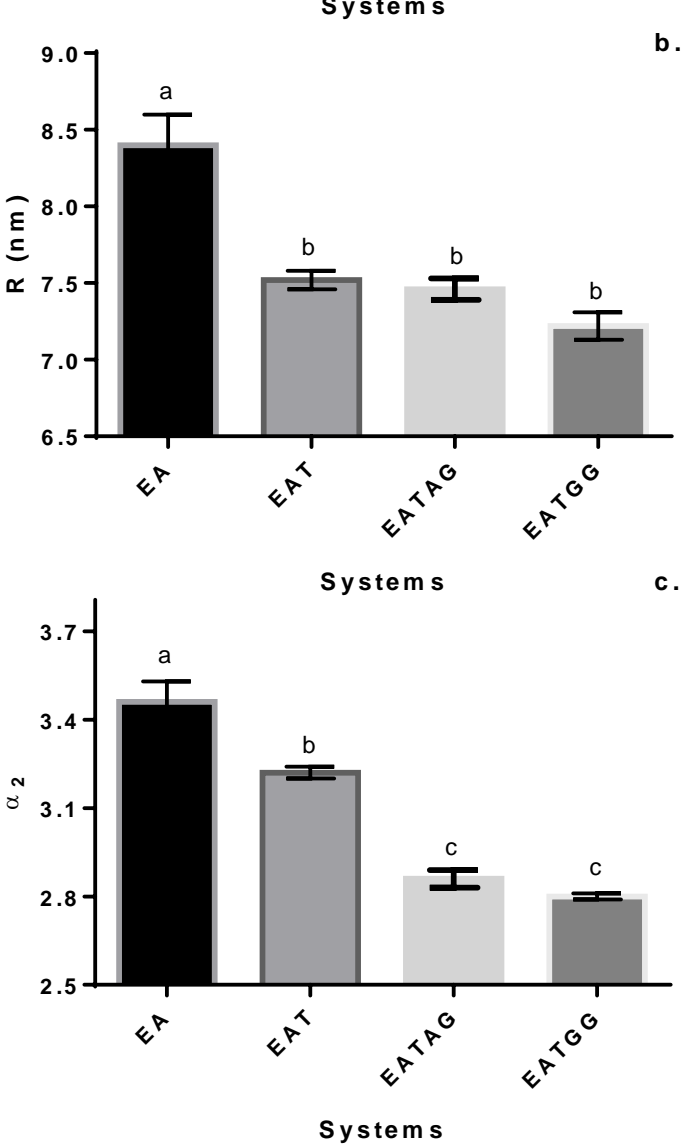

Figure 3. Parameter $\alpha_{1}$ (a) and $\alpha_{2}$ (c) of the microstructure derived from log-log SAXS profiles and $\mathrm{R}$ (outer radius of the fibrils) (b), deduced from the maxima obtained on Kratky plots. Standard deviations values are included. Different letters on the columns (a-c) indicate 
significant differences between values with $p<0.05$. E: enzyme; A: alginate; T: trehalose; AG: arabic gum; GG: guar gum.

Effects of beads composition and thermal treatments on lactase activity preservation

$\beta$-galactosidase activity after beads generation was evaluated as an activity index (\%), which was determined as the amount of active enzyme in the beads with different composition related to the enzyme/alginate system (equation 1). Besides, the enzyme activity of the beads subjected to thermal treatments was studied as remaining activity (\%), which relates the activity of the beads after the treatment with regard to the enzyme activity of the same composition before it (equation 2). Figure 4 shows the activity index and the remaining activity of lactase.

Immediately after beads generation, the beads that only contain alginate showed the highest activity index comparing with the rests of compositions. However, the changes in beads formulation had showed major effects on the conservation of lactase activity subjected to different treatments. Thus, the enzymatic activity of the alginate systems decreases significantly at $24 \mathrm{~h}$ of storage at $4{ }^{\circ} \mathrm{C}$ and with more intensive treatments such as freezing, the activity is practically zero. In contrast, the beads containing trehalose showed significant higher remaining activity values after subjecting the beads to freezing or freezing/thawing cycles. As was previously reported by Santagapita et al. ${ }^{13}$, trehalose greatly improves the enzymes stability during thermal treatments, but do not show any protective effect during beads generation.

After four cycles of freezing/thawing, the beads with guar gum showed significant highest remaining enzymatic activity, close to $90 \%$, than any of the other systems. Thus, the addition of guar gum as excipient improves the stability of the protein probably due to the improvement in 
characteristics of the beads. Since changes in molecular mobility and thermal properties of the systems such glass transition temperature and freezable/unfreezable water mass could explain the present results, NMR and DSC analysis were conducted.

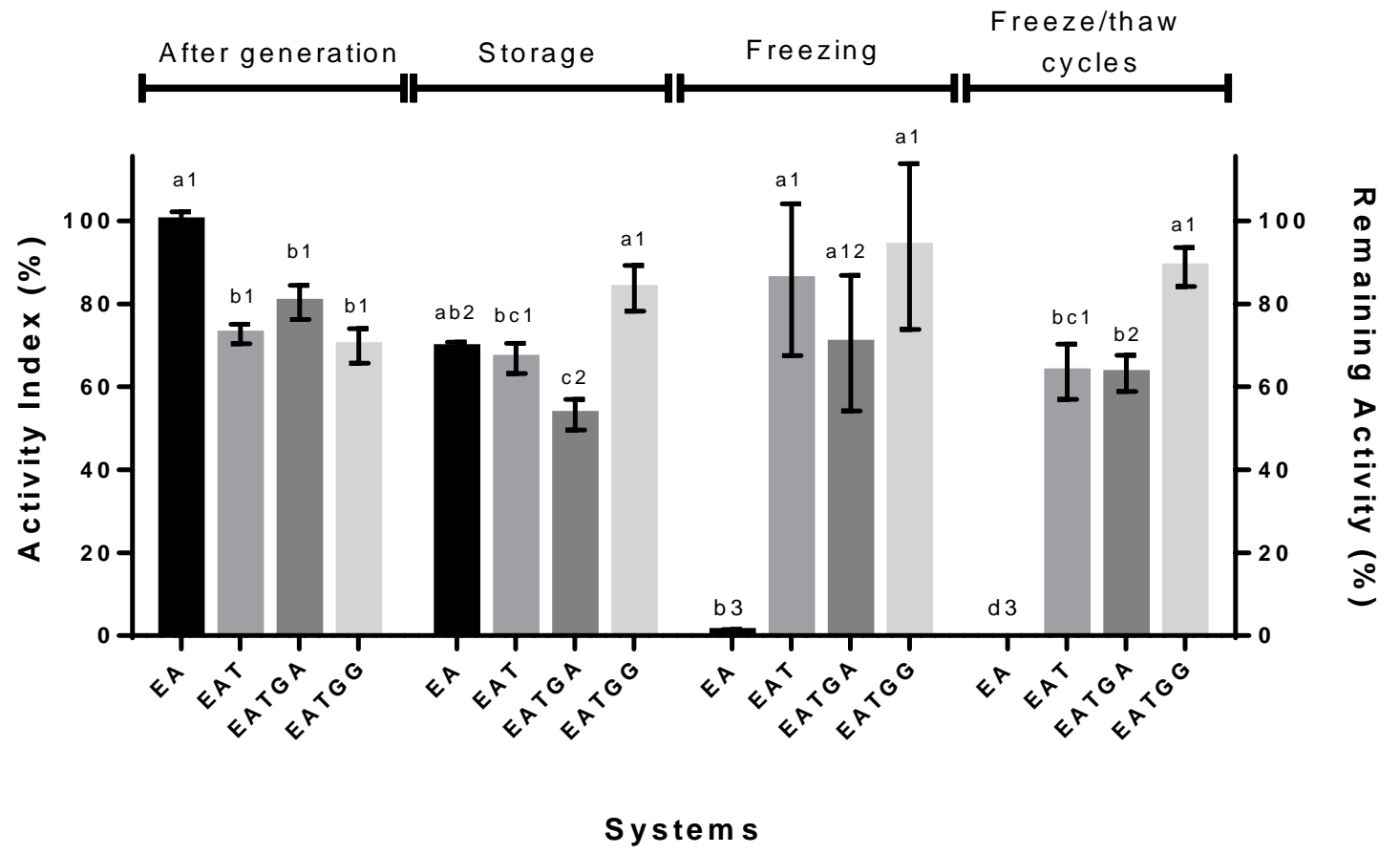

Figure 4. Activity index of lactase (\%) in beads after generation and remaining activity of lactase (\%) after different treatments: storage $\left(48 \mathrm{~h}\right.$ at $\left.4{ }^{\circ} \mathrm{C}\right)$, frozen $\left(24 \mathrm{~h}\right.$ at $\left.-18{ }^{\circ} \mathrm{C}\right)$ and four freeze/thaw cycles $\left(-196 / 4{ }^{\circ} \mathrm{C}\right)$. E: enzyme; A: alginate; T: trehalose; AG: arabic gum; GG: guar gum. For a certain treatment bars with the same letter (a-d) indicate no significant differences $(p<0.05)$; for beads of same composition bars with the same number (1-3) have no significant differences between treatments $(p<0.05)$.

It is already known that the thermal properties of the glassy matrix produced during freezing of the beads could have a direct impact on enzyme stability. Table 2 shows the glass transition temperature $\left(T_{g}\right)$, the specific heat capacities variation associated to $T_{g}(\Delta c p)$, the crystallization and melting enthalpies $(\Delta \mathrm{H})$, the onset temperatures of ice melting $\left(\mathrm{T}_{\mathrm{m}}{ }^{\prime}\right)$ and the mass fraction of 
unfreezable water $\left(\mathrm{x}_{\mathrm{nfw}}\right)$. The beads containing trehalose had a $\mathrm{T}_{\mathrm{g}}$ value near $-65{ }^{\circ} \mathrm{C}$ and no significant differences were found between the different compositions. On the other hand, it was not possible to obtain a $T_{g}$ value for EA beads, probably due to the $T_{g}$ of polymers (alginate, in this case) is much harder to be observed, since is wider (it is develop in a longer range of temperatures) and of lower $\Delta \mathrm{cp}$ than the transition observed for smaller carbohydrates like trehalose. ${ }^{35}$ This fact was already reported by Santagapita et al. ${ }^{11}$ for dehydrated beads containing invertase. It is interesting to observe than the $T_{g}$ values obtained for trehalose containing beads is lower than the $\mathrm{T}_{\mathrm{g}}$ ' value of $-41{ }^{\circ} \mathrm{C}$ reported by Roos \& Pehkonen, ${ }^{36}$ for trehalose. This is due to the fact that the determined $T_{g}$ is not the $T_{g}{ }^{`}$ of the systems (there is still water associated to the matrix, as revealed by the small crystallization event observed post $\mathrm{T}_{\mathrm{g}}$ ), and also that the glassy matrix formed includes both trehalose and alginate (plus water). Regarding enzyme stability, the outstanding bioprotective properties of trehalose are not only explained by the capacity of the sugar to form glassy structures, in which biomolecules are kinetically stabilized, but also by the specific hydrogen bond interactions established between the sugar and the biomolecule during freezing or drying. ${ }^{37}$ Also, no significant differences among the specific heat capacities variations between the systems can be appreciated, which implies that the glassy matrix formed in each bead along freezing is similar in all cases. ${ }^{15}$ Then, it seems that the differences observed in EATGG beads respect to the other systems are not due to changes on $\mathrm{T}_{\mathrm{g}}$ or in the glassy matrix formed. However, $\mathrm{T}_{\mathrm{m}}$ ' showed significative differences among the beads. This parameter has strong technological implications, since is the lowest temperature at which the frozen material could be stored without melting. For the beads containing trehalose, the obtained values are quite higher than the $\mathrm{T}_{\mathrm{m}}{ }$ of trehalose, ${ }^{36}$ due to the alginate and/or biopolymers presence. In fact, the presence of hydrocolloids reduced the $\mathrm{T}_{\mathrm{m}}{ }^{`}$ value. This is 
consistent with the calculation of the unfrozen water associated to the bead matrix $\left(\mathrm{x}_{\mathrm{nfw}}\right)$ : in the absence of trehalose, the EA beads showed much higher water content associated to the matrix. The presence of gums, however, significantly reduced the $\mathrm{x}_{\mathrm{nfw}}$, due to gums ability to associate water.

Table 2. Glass transition temperature $\left(T_{g}\right)$, change in heat capacity at $T_{g}(\Delta c p)$, crystallization and melting enthalpies, and onset melting temperature $\left(T_{m}{ }^{\prime}\right)$ obtained by DSC. The mass fraction corresponding to non-freezable water was calculated according to equation 3. E: enzyme; A: alginate; T: trehalose; AG: arabic gum; GG: guar gum. Standard deviation values are included.

\begin{tabular}{|c|c|c|c|c|c|c|c|c|c|c|c|c|c|}
\hline & \multicolumn{2}{|c|}{ Glass transition } & \multirow{2}{*}{\multicolumn{3}{|c|}{$\begin{array}{c}\text { Crystallization } \\
\Delta \mathrm{H}(\mathrm{J} / \mathrm{g})\end{array}$}} & \multicolumn{6}{|c|}{ Melting } & \multirow{2}{*}{\multicolumn{2}{|c|}{$\mathrm{X}_{\mathrm{nfw}}$}} \\
\hline Systems & $\mathrm{T}_{\mathrm{g}}\left({ }^{\circ} \mathrm{C}\right)$ & $\Delta \mathrm{cp}(\mathrm{J} / \mathrm{gK})$ & & & & \multicolumn{3}{|c|}{$\Delta \mathrm{H}(\mathrm{J} / \mathrm{g})$} & \multicolumn{3}{|c|}{$\mathrm{T}_{\mathrm{m}}{ }^{\prime}\left({ }^{\circ} \mathrm{C}\right)$} & & \\
\hline EA & - & - & & - & & -278.8 & \pm & $0.6^{\mathrm{a}}$ & -1.82 & \pm & $0.06^{\mathrm{d}}$ & 0.135 & $\pm 0.002^{c}$ \\
\hline EAT & $-64 \pm 2^{a}$ & $0.12 \pm 0.05^{\mathrm{a}}$ & 1.3 & \pm & $0.2^{\mathrm{ab}}$ & -232 & \pm & $1^{\mathrm{b}}$ & -7.53 & \pm & $0.02^{\mathrm{a}}$ & 0.187 & $\pm 0.002^{\mathrm{a}}$ \\
\hline EATAG & $-65 \pm 2^{a}$ & $0.12 \pm 0.05^{\mathrm{a}}$ & 0.765 & $5 \pm$ & $0.007^{b}$ & -245 & \pm & $5^{\mathrm{bc}}$ & -6.7 & \pm & $0.1^{\mathrm{b}}$ & 0.157 & $\pm 0.005^{\mathrm{b}}$ \\
\hline EATGG & $-65 \pm 1^{a}$ & $0.12 \pm 0.05^{\mathrm{a}}$ & 1.595 & $5 \pm$ & $0.007^{\mathrm{a}}$ & -246.01 & \pm & $0.06^{c}$ & -5.50 & \pm & $0.05^{c}$ & 0.158 & $\pm 0.001^{\mathrm{b}}$ \\
\hline
\end{tabular}

a-d Different letters on the columns indicate significant differences between means $(p<0.05)$.

Longitudinal and transverse relaxation times obtained at $25{ }^{\circ} \mathrm{C}$ were measured by LF-NMR and are shown in Table 3.

$\mathrm{T}_{1}$ (or spin-lattice) and $\mathrm{T}_{2}$ (or spin-spin) relaxations represent the efficiency of the protons to relax in the $\mathrm{z}$ and $\mathrm{x}-\mathrm{y}$ directions, respectively. In both cases, the principal mechanism involved in the relaxation is magnetic field fluctuations. The main source of these fluctuations arises from molecular motion. For larger molecules like biopolymers, $T_{1}>T_{2}$, since the correlation time (the time it takes an average molecule to rotate one radian) is between $10^{-8}-10^{-5} .{ }^{38}$ This behavior was observed for our systems. The presence of trehalose reduced $T_{1}$, which is probably related to 
the lower correlation time of this molecule respect to alginate, even though the amount of protons contributed by trehalose is small respect to those contributed by water (as manifested by amplitude values). The presence of gums increases the $T_{1}$ respect to EAT beads. The CMPG sequence for $\mathrm{T}_{2}$ allows the analysis of systems with high proton mobility ( $\left.>1 \mathrm{~ms}\right)$. The beads showed two $\mathrm{T}_{2}$ times, in the range 54-66 ms and 379-710 ms, respectively. These two relaxation times were consistent to the ones determined by Aguirre Calvo at al. ${ }^{31}$ and Rayment et al. ${ }^{39}$ As expected, the obtained $T_{2}$ values were lower than the correspondent to pure water due to the reduced flexibility of the biopolymers chains. ${ }^{40}$ Among the amplitudes, it is possible to observe that more than $85 \%$ of protons contributed to the first population (lower $\mathrm{T}_{2}$ ). There were no significant differences between amplitudes among the beads of different composition, as previously observed, ${ }^{31}$ with the only exception of EAT and EA for $\mathrm{A}_{22}$. However, the $\mathrm{T}_{2}$ times were affected by composition, being especially high for $\mathrm{EA}$ beads for $\mathrm{T}_{22}$ and low for $\mathrm{T}_{21}$.

It is important to highlight that the magnitude of $\mathrm{T}_{2}$ reduction depends on the aggregation state and if the system is gelled or not. The NMR water proton response in gels or diluted polysaccharides systems is modulated by the exchange between water and biopolymers protons. ${ }^{41,42}$ As a consequence, there are small differences among the systems in terms of populations (two for all the beads) and in terms of relative amplitudes. The second proton population corresponds to the water with high mobility, corresponding to the less associated water to biopolymers/sugar/gelled structure. Instead, the first proton population corresponds to the associated water (first hindrance layers), and even the absorbed water (to the solid matrix) and the solids itself (even though in a low proportion). The presence of trehalose strongly influenced the $\mathrm{T}_{22}$, due to the fact that trehalose can be found in the entire bead, interacting with all the components. Only guar gum provokes a significant increment in $T_{21}$ with respect to 
trehalose-containing beads. $\mathrm{T}_{22}$ shows also a higher mean value, even though this increment was not significant. This increment is translated in a slightly higher mobility in the EATGG beads than in the other systems, which could account for a higher degree of rearrangement of the protons excipients inside the beads, allowing a higher degree of interaction with the enzyme.

Table 3. Longitudinal $\left(T_{1}\right)$, transversal $\left(T_{21}\right.$ and $\left.T_{22}\right)$ relaxation times and their correspondent amplitudes of beads containing lactase. E: enzyme; A: alginate; T: trehalose; AG: arabic gum; GG: guar gum. Standard deviation values are included.

\begin{tabular}{|c|c|c|c|c|c|c|}
\hline Systems & $\begin{array}{c}\text { Amplitude }_{1} \\
\text { (\%) }\end{array}$ & $\mathrm{T}_{1}(\mathrm{~ms})$ & $\begin{array}{c}\text { Amplitude }_{21} \\
\text { (\%) }\end{array}$ & $\mathrm{T}_{21}(\mathrm{~ms})$ & $\begin{array}{c}\text { Amplitude }_{22} \\
\text { (\%) }\end{array}$ & $\mathrm{T}_{22}(\mathrm{~ms})$ \\
\hline EA & $-181 \pm 1^{\mathrm{a}}$ & $1550 \pm 10^{\mathrm{a}}$ & $85.5 \pm 0.3^{\mathrm{a}}$ & $53.9 \pm 0.3^{c}$ & $14.5 \pm 0.3^{\mathrm{a}}$ & $710 \pm 20^{a}$ \\
\hline EAT & $-182 \pm 9^{a}$ & $1292 \pm 12^{\mathrm{d}}$ & $87.1 \pm 0.2^{\mathrm{a}}$ & $57 \pm 1^{\mathrm{bc}}$ & $12.9 \pm 0.2^{\mathrm{b}}$ & $403 \pm 47^{\mathrm{b}}$ \\
\hline EATAG & $-193 \pm 1^{a}$ & $1338 \pm 6^{\mathrm{c}}$ & $86.6 \pm 0.9^{a}$ & $58.1 \pm 0.3^{b}$ & $13.3 \pm 0.9^{\mathrm{ab}}$ & $379 \pm 62^{\mathrm{b}}$ \\
\hline EATGG & $-194 \pm 2^{a}$ & $1395 \pm 15^{b}$ & $86 \pm 1^{\mathrm{a}}$ & $66 \pm 1^{\mathrm{a}}$ & $14 \pm 1^{\mathrm{ab}}$ & $495 \pm 69^{\mathrm{ab}}$ \\
\hline
\end{tabular}

a-d Different letters on the columns indicate significant differences between means $(p<0.05)$.

\section{CONCLUSIONS}

Alginate-Ca(II) beads containing lactase were successfully produced by the dropping method. Even though the inclusion of secondary excipients negatively influences the enzyme recovery with $20-30 \%$ losses, trehalose addition was critical for enzyme conservation during freezing and freeze/thawing treatments. Besides, the presence of guar gum improved the enzyme stability in a better way than in other trehalose containing beads during storage at $4{ }^{\circ} \mathrm{C}$ and freeze/thawing. This effect was probably related to a slighter higher molecular mobility on EATGG beads, which could account for a higher degree of rearrangement of the protons excipients inside the beads, allowing a higher degree of interaction with the enzyme. 
The establishment of glassy matrix during freezing was critical to assure the maintenance of the lactase activity. The obtained glassy matrices showed similar $\mathrm{T}_{\mathrm{g}}$ and $\Delta \mathrm{cp}$ values in all trehalose containing systems, but the inclusion of gums slightly increased the $T_{m}$ ' values, representing a valuable technological improvement.

The microstructure of the alginate-Ca(II) beads showed interesting results: the presence of secondary excipients affected the microstructure, showing rods with smaller cross-sectional radius $\mathrm{R}$ and with lower compactness within the rods $\left(\alpha_{2}\right)$ than alginate-Ca(II) beads. However, there were no significant changes in rods interconnection $\left(\alpha_{1}\right)$. This lower compactness of the rods in the presence of trehalose could also explain the higher enzyme activity recovered, having the enzyme great possibilities of being located within the rods, increasing the possibility of establish more effective interactions.

The addition of both gums resulted in a significant increment of the bead size. However, arabic gum containing beads showed the highest circularity, and the guar gum containing ones the lowest. In this case, the increment in viscosity produced by the addition of guar gum accounts for a higher deformation during dropping. Further analysis should be conducted by changing the guar gum concentration, in order to optimize all the analyzed parameters.

\section{ACKNOWLEDGEMENTS}

The author María Victoria Traffano Schiffo wants to thank "Programa para la Formación de Personal Investigador (FPI)” Pre-doctoral Program of the Universitat Politècnica de València (UPV) for support her PhD studies and also her mobility to Argentina. This work was supported by the Brazilian Synchrotron Light Laboratory (LNLS, Brazil, proposal SAXS1-20160278), Universidad de Buenos Aires (UBACyT 20020130100610BA), Agencia Nacional de Promoción 
Científica y Tecnológica (ANPCyT PICT 20130434 and 2013 1331), CIN-CONICET (PDTS $2015 n^{\circ}$ 196), and Consejo Nacional de Investigaciones Científicas y Técnicas. The authors acknowledge Dr. Pombero of R.D.C. for the useful discussions. PRS is a member of CONICET (Argentina).

\section{REFERENCES}

(1) Geiger, B.; Nguyen, H. M.; Wenig, S.; Nguyen, H. A.; Lorenz, C.; Kittl, R.; ... Nguyen, T. H. Biochem. Eng. J. 2016, 116, 45-53.

(2) Pereira-Rodríguez, Á.; Fernández-Leiro, R.; González-Siso, M. I.; Cerdán, M. E., Becerra, M.; Sanz-Aparicio, J. J. Struct. Biol. 2012, 177, 392-401.

(3) Banaszewska, A., Cruijssen, F., Claassen, G. D. H.; van der Vorst, J. G. A. J. J. Dairy Sci. 2014, 97, 1893-1908.

(4) Mlichová, Z.; Rosenberg, M. J. Food Nutr. Res. 2006, 45, 47-54.

(5) Erich, S.; Kuschel, B.; Schwarz, T.; Ewert, J.; Böhmer, N.; Niehaus, F.; ... Fischer, L. J. Biotechnol. 2015, 210, 27-37.

(6) Harju, M.; Kallioinen, H.; Tossavainen, O. Int. Dairy J. 2012, 22, 104-109.

(7) Husain, Q. Crit. Rev. Biotechnol. 2010, 30, 41-62.

(8) Josef, E.; Zilberman, M.; Bianco-Peled, H. Acta Biomater. 2010, 6, 4642-4649.

(9) Khattak, S. F.; Chin, K. S.; Bhatia, S. R.; Roberts, S. C. Biotechnol. Bioeng. 2007, 96, 156166. 
(10) Rehman, H. U.; Aman, A.; Silipo, A.; Qader, S. A. U.; Molinaro, A.; Ansari, A. Food Chem. 2013, 139, 1081-1086.

(11) Santagapita, P. R.; Mazzobre, M. F.; Buera, M. P. Food Res. Int. 2012, 47, 321-330.

(12) Córdoba, A. L.; Deladino, L.; Martino, M. Carbohyd. Polym. 2013, 95, 315-323.

(13) Santagapita, P. R.; Mazzobre, M. F.; Buera, M. P. Biomacromolecules 2011, 12, 31473155.

(14) Li, X. Y.; Chen, X. G.; Liu, C. S.; Peng, H. N.; Cha, D. S. Dry. Technol. 2008, 26, 895901.

(15) Santagapita, P. R.; Buera, M. P. J. Non-Cryst. Solids 2008, 354, 1760-1767.

(16) Busch, V. M.; Pereyra-Gonzalez, A.; Šegatin, N.; Santagapita, P. R.; Ulrih, N. P.; Buera, M. P. LWT-Food Sci. Technol. 2017, 75, 227-235.

(17) Estevinho, B. N.; Damas, A. M.; Martins, P.; Rocha, F. Food Res. Int. 2014, 64, 134-140.

(18) George, M.; Abraham, T. E. Int. J. Pharm. 2007, 335, 123-129.

(19) Waters, D. J.; Engberg, K.; Parke-Houben, R.; Hartmann, L.; Ta, C. N.; Toney, M. F.; Frank, C. W. Macromolecules 2010, 43, 6861-6870.

(20) Sonego, J. M.; Santagapita, P. R.; Perullini, M.; Jobbágy, M. Dalton Trans. 2016, 45, 10050-10057.

(21) Agulhon, P.; Robitzer, M.; David, L.; Quignard, F. Biomacromolecules 2012, 13, 215220. 
(22) Dashevsky, A. Int. J. Pharm. 1998, 161, 1-5.

(23) Ullmann’s Encyclopaedia of Industrial Chemistry, 5th ed.; Elvers, B., Ed.; VCH. 1995.

(24) Austin, L.; Bower, J. J.; Muldoon, C. P. Int. Sym. Contr. Release Bioact. Mater. 1996, 23, 739-740.

(25) Aguirre Calvo, T.; Santagapita, P. J. Qual. Reliab. Eng. 2016, 2016, 1-7.

(26) Park, Y. K.; Santi, M. S. S.; Pastore, G. M. J. Food Sci. 1979, 44, 100-103.

(27) Tylewicz, U.; Panarese, V.; Laghi, L.; Rocculi, P.; Nowacka, M.; Placucci, G.; Dalla Rosa, M. Food Biophys. 2011, 6, 327-333.

(28) Belotti, M.; Martinelli, A.; Gianferri, R.; Brosio, E. Phys. Chem. Chem. Phys. 2010, 12, 516-522.

(29) Carr, H. Y.; Purcell, E. M. Phys. Rev. 1954, 94, 630.

(30) Meiboom, S.; Gill, D. Rev. Sci. Instrum. 1958, 29, 688-691.

(31) Aguirre Calvo, T. R; Busch, V. M.; Santagapita, P. R. LWT-Food Sci. Technol. 2017, 77, 406-412.

(32) Busch, V. M.; Kolender, A. A.; Santagapita, P. R.; Buera, M. P. Food Hydrocolloid. 2015, 51, 495-502.

(33) Vasile, F. E.; Martinez, M. J.; Ruiz-Henestrosa, V. M. P.; Judis, M. A.; Mazzobre, M. F. Food Hydrocolloid. 2016, 56, 245-253. 
(34) Fang, Y.; Al-Assaf, S.; Phillips, G. O.; Nishinari, K.; Funami, T.; Williams, P. A.; Li, L. J. Phys. Chem. B 2007, 111, 2456-2462.

(35) Katayama, D. S.; Carpenter, J. F.; Manning, M. C.; Randolph, T. W.; Setlow, P.; Menard, K. P. J. Pharm. Sci. 2008, 97, 1013-1024.

(36) Roos, Y. H.; Pehkonen, K. S. In Water Properties in Food, Health, Pharmaceutical and Biological Systems: ISOPOW 10. Reid, D. S., Sajjaanantakul, T., Lillford, P.J.,Charoenrein, S., Eds.; Wiley-Blackwell, a John Wiley \& Sons, Inc.: Ames, Iowa, USA. 2010; pp 285-290.

(37) Schebor, C.; Mazzobre, M. F.; Buera, M. P. Carbohyd. Res. 2010, 345, 303-308.

(38) Bloembergen, N.; Purcell, E.M.; Pound R.V. Phys. Rev. 1948, 73, 679.

(39) Rayment, P.; Wright, P.; Hoad, C.; Ciampi, E.; Haydock, D.; Gowland, P.; Butler, M. F. Food Hydrocolloid. 2009, 23, 816-822.

(40) Ablett, S.; Lillford, P. J.; Baghdadi, S. M. A.; Derbyshire, W. Am. Chem. Soc. Symp. Series 1976, 34, 344-359.

(41) Hills, B. P.; Cano, C.; Belton, P. S. Macromolecules 1991, 24, 2944-2950.

(42) Kimberlee, P.; Adrian, C. T.; Laurence, H. Carbohyd. Res.1993, 246, 43-49. 
Table of Contents graphic

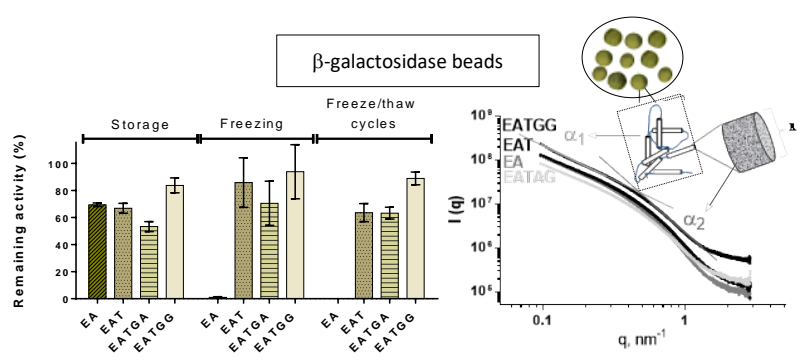

